\title{
Use of Starter Cultures in Olives: A Not-Correct Use Could Cause a Delay of Performances
}

\author{
Marianne Perricone, Maria Rosaria Corbo, Milena Sinigaglia, Antonio Bevilacqua*
}

Department of Agriculture, Food and Environmental Science, University of Foggia, Foggia, Italy.

Email: *a.bevilacqua@unifg.it, ${ }^{*}$ abevi@libero.it

Received December $10^{\text {th }}, 2012$; revised January $13^{\text {th }}, 2013$; accepted January $21^{\text {st }}, 2013$

Copyright (C) 2013 Marianne Perricone et al. This is an open access article distributed under the Creative Commons Attribution License, which permits unrestricted use, distribution, and reproduction in any medium, provided the original work is properly cited.

\begin{abstract}
The role of lactic acid bacteria for a correct course of fermentation of table olives has been extensively reviewed and it is a common idea that the inoculum of selected strains could exert a strong benefit for product quality; however, the basic assumption of this research is that a not-correct preparation of starter could affect its performances in brines and delay the benefit of a starter inoculum. Thus, some selected strains of LAB (lactic acid bacteria) and yeasts were inoculated into brines of Bella di Cerignola olives (Spanish style), as a single starter (LAB or yeasts) or a combined preparation (LAB + yeasts) and compared to a natural fermentation, focusing on the performances of the process (acidification, production of lactic acid) and trying to verify the basic assumption. LAB and yeasts were grown in the opportune lab media and then directly inoculated in brine after the lye treatment. LAB exerts a kind of benefit (increased content of lactic acid) only for 2 - 3 weeks; then, the inoculated samples behave in the same way as not-inoculated ones. Thus, this research underlined that a starter culture, not prepared in the correct way, could not be useful to guide the fermentation.
\end{abstract}

Keywords: Olives; Lactic Acid Bacteria; Yeasts; Delay in Fermentation; Starter

\section{Introduction}

Fermentation of table olives starts spontaneously and is strongly influenced by olive cultivar, indigenous microbiota and methodological factors, such as temperature and salt concentration in the brine [1].

Moreover, olive fermentation relies on a complex microbiota, including Enterobacteriaceae, lactic acid bacteria and other genera of Gram positive microorganisms and yeasts; the traditional fermentations are usually based on the maintenance of this association [2].

In a natural olive fermentation after an initial stage, characterised by the growth of Gram negative bacteria, lactic acid bacteria and yeasts coexist until the end of fermentation; in particular, in Bella di Cerignola olives, yeasts were found at concentrations of approximately 5 $6 \mathrm{log} \cdot \mathrm{cfu} / \mathrm{g}$ on olives and $6 \mathrm{log} \cdot \mathrm{cfu} / \mathrm{ml}$ in the brines $[3,4]$. On the other hand, Hernandèz, Martin, Aranda, PèrezNevado and Còrdoba [5] recovered a yeast number of about $3.0 \mathrm{log} \cdot \mathrm{cfu} \cdot \mathrm{g} / \mathrm{l}$ and $4.9 \mathrm{log} \cdot \mathrm{cfu} / \mathrm{ml}$ in Spanish green olives and their brines, respectively. The role of lactic acid bacteria for a correct course of fermentation of table

"Corresponding author. olives has been extensively reviewed and it is a common idea that the inoculum of selected strains could exert a strong benefit for product quality [2].

For a better course of the process and to control naturally occurring microflora, many authors recommended the inoculation of brine with commercial strains; the use of suitable Lactobacillus plantarum starter cultures has the potential to improve the microbiological control of the process, increase the lactic acid yield and, accordingly, provide the production of Spanish-style fermented green olives of consistently high quality [6]. Recently, some authors proposed a mixed starter, containing a combination of LAB and yeasts [4].

During the fermentation, weak acidification rates are often registered, because most of the sugars and nutrients are lost by the effect of lye treatment and strong washing, thus $\mathrm{pH}$ is often unsuitable for a safe storage of product [7].

However, many times a delay or a lack of fermentation of olives, especially those of the Manzanilla variety, occurs and there is no explanation for this phenomenon; many variables can affect the progress of lactic acid fermentation such as salt concentration, temperature, nutria- 
nutrient content, inhibitors and others. Earlier investigations related the difficulties of LAB growth in olive brines with the presence of polyphenols [8].

However, many times the incomplete acidification cannot be related to phenols (Bevilacqua, unpublished results); the basic assumption of this research is that a notcorrect preparation of starter could affect its performances in brines and delay the benefit of a starter inoculum.

Thus, some selected strains of LAB and yeasts were inoculated into brines of Bella di Cerignola olives, as a single starter (LAB or yeasts) or a combined preparation (LAB + yeasts) and compared to a natural fermentation, focusing on the performances of the process (acidification, production of lactic acid) and trying to verify the basic assumption.

\section{Materials and Methods}

\subsection{Strains}

4 strains of Lactobacillus plantarum were used in this study: the strains c1, c16 and c19 isolated from a natural fermentation of Bella di Cerignola olives [9], whereas the isolate DSMZ 2601 was purchased from a Public Collection (Deutsche Sammlung von Mikroorganismen und Zellkulturen, Braunschweig, Germany).

Moreover, 3 strains of Candida spp. (labelled as 2251-66 and isolated from a natural fermentation of Bella di Cerignola olives) were used as selected yeasts; in particular the strains 22 and 51 were identified as C. famata, while the strain 66 as C. guilliermondii [2].

The strains of $L b$. plantarum, stored at $-20^{\circ} \mathrm{C}$ in MRS broth (Oxoid, Milan, Italy) added with $33 \%$ of sterile glycerol (J.T. Baker, Milan, Italy), were grown over 2 passages in MRS broth, incubated at $30^{\circ} \mathrm{C}$ for $48 \mathrm{~h}$. The strains of Candida spp. were maintained on Sabouraud Dextrose Agar slants (Oxoid), stored at $4^{\circ} \mathrm{C}$ and transferred monthly; before each assay, the strains were grown in Sabouraud broth (Oxoid), incubated at $25^{\circ} \mathrm{C}$ for $48 \mathrm{~h}$.

\subsection{Inocula Preparation}

LAB cocktail was prepared as follows: $50 \mathrm{ml}$ of the culture of each strain were centrifuged at $4000 \mathrm{rpm}$ for 10 min. then, the supernatant was discarded and $50 \mathrm{ml}$ of saline solution $(9 \%$ of $\mathrm{NaCl})$ was added to the pellet (cell suspension).

The cocktail was prepared by mixing $50 \mathrm{ml}$ of cell suspension for each LAB strain to obtain a final volume of $200 \mathrm{ml}$; this volume was used for the inoculation of 10 1 of brine (the level of each strain was about $8 \log \cdot \mathrm{cfu} /$ $\mathrm{ml})$.

Concerning yeast cocktail, $70 \mathrm{ml}$ of the culture of each strain were centrifuged at $4000 \mathrm{rpm}$ for $10 \mathrm{~min}$; then, the pellet was suspended in $70 \mathrm{ml}$ of brine. Yeast cocktail was prepared by mixing cell suspension of each strain (ca. $6-7 \log \cdot \mathrm{cfu} / \mathrm{ml}$ ), thus attaining a final volume of $210 \mathrm{ml}$. This suspension was used for the inoculation of 101 of brine (high inoculum); for the batches inoculated with a low level of yeasts (low inoculum), the suspension was diluted at $5 \log \cdot \mathrm{cfu} / \mathrm{ml}$ and then used for brine inoculation.

\subsection{Olive Preparation and Fermentation}

The fermentation was performed on Bella di Cerignola olives, size GGG (i.e. 70 to 80 olives $/ \mathrm{kg}$ ). After harvesting, olives were subjected to grading, to remove fruits with visible damages, washed with tap water and treated with lye (1.3\%) for 12 to $15 \mathrm{~h}$. After 2 washings ( 2 to $3 \mathrm{~h}$ and 12 to $13 \mathrm{~h}$ ), olives were brined $(9 \%$ of $\mathrm{NaCl}$ ) and inoculated with LAB and/or yeasts.

The fermentation took place in vessels of $25 \mathrm{l}$, containing $10 \mathrm{~kg}$ of olives and 101 of brine; olives were maintained dipped in the brines through a grid. The vessels were stored at room temperature for the entire fermentation and mixed periodically to avoid the formation of a mould layer on the top of the brine. $\mathrm{NaCl}$ was checked periodically and maintained for the entire fermentation at $8 \%-9 \%$.

Table 1 shows the different batches prepared for the analysis.

Although performed at laboratory level, the conditions used for the fermentation (ratio olive/brine 1:1, use of a grid, mixing periodically the brines, fermentation at room temperature) mimic the conditions encountered throughout olive production in Apulian region.

\subsection{Microbiological Analyses}

Microbiological analyses were performed both on olives and brines throughout the entire fermentation; $20 \mathrm{~g}$ of olives were diluted with sterile saline solution $(0.9 \%$ $\mathrm{NaCl}$ ) and homogenized through a Sterilmixer (Pbi International, Milan, Italy) at 16,500 rpm for $2 \mathrm{~min}$. Serial dilutions of olive homogenates and brines were performed and plated onto selective media. All the media and the supplements were purchased from Oxoid.

Table 1. Batches prepared for the fermentation assays ( $T$, olives; $\mathrm{S}$, brines).

\begin{tabular}{cc}
\hline T1/S1 & Control \\
T2/S2 & $\begin{array}{c}\text { Batch inoculated with LAB } \\
(6-7 \mathrm{log} \cdot \mathrm{cfu} / \mathrm{ml})\end{array}$ \\
T3/S3 & $\begin{array}{c}\text { Batch inoculated with yeasts } \\
\text { (high inoculum, } 5 \mathrm{log} \cdot \mathrm{cfu} / \mathrm{ml})\end{array}$ \\
$\mathrm{T} 4 / \mathrm{S} 4$ & Batch inoculated with LAB and yeasts (high inoculum) \\
T5/S5 & $\begin{array}{c}\text { Batch inoculated with LAB and yeasts } \\
\text { (low inoculum, ca. } 3 \mathrm{log} \cdot \mathrm{cfu} / \mathrm{ml})\end{array}$ \\
\hline
\end{tabular}


The media and the conditions were the following:

1) Mesophilic bacteria: Plate Count Agar (PCA), incubated at $30^{\circ} \mathrm{C}$ for $24-48 \mathrm{~h}$.

2) Spore-former bacteria: PCA, incubated at $30^{\circ} \mathrm{C}$ for $24-48 \mathrm{~h}$. The evaluation of spore-former bacteria was carried out after heat-shocking olive homogenates and brines at $80^{\circ} \mathrm{C}$ for $10 \mathrm{~min}$.

3) LAB: MRS Agar, added with $0.17 \mathrm{~g} / 1$ of cycloheximide (Sigma-Aldrich, Milan, Italy), incubated at $30^{\circ} \mathrm{C}$ under anaerobic conditions for $48-72 \mathrm{~h}$.

4) Yeasts: Sabouraud Dextrose Agar, added of $0.1 \mathrm{~g} / 1$ of chloramphenicol (C. Erba, Milan, Italy), incubated at $25^{\circ} \mathrm{C}$ for $2-4$ days.

5) Pseudomonadaceae: Pseudomonas Agar Base, added with $\mathrm{CFC}$ selective supplement (containing cetrimide, a selective antibiotic for pseudomonas), incubated at $25^{\circ} \mathrm{C}$ for $48-72 \mathrm{~h}$.

6) Staphylococci: Baird Parker Agar Base, added with egg yolk tellurite emulsion and incubated at $37^{\circ} \mathrm{C}$ for 24 $48 \mathrm{~h}$.

7) Enterobacteriaceae: Violet Red Bile Glucose Agar (VRBGA), incubated at $37^{\circ} \mathrm{C}$ for $18-24 \mathrm{~h}$.

\section{5. pH Evaluation}

$\mathrm{pH}$ measurements were performed on olive homogenates and brines through a pH-meter Crison 2001 (Crison Instruments, Barcelona, Spain).

\subsection{Determination of Organic Acids}

The content of D- and L-lactic acids, as well as the concentration of acetic, citric, D- and L-malic acids, D-glucose and D-fructose in the brines was determined through enzymatic kits (Megazyme, Bray, Ireland) just after the brining (beginning of the fermentation) and after $7,21,28,35$ and 42 days of fermentation. The analyses were performed as suggested by the producer.

\subsection{Statistical Analyses}

All the analyses were performed in duplicate over 2 independent batches, labelled A and B. Data were submitted to one-way analysis of variance (one-way ANOVA) and Tukey's test $(\mathrm{P}<0.05)$ through the software Statistica for Windows version 10.0 (Statsoft, Tulsa, Okla., USA).

\section{Results}

\subsection{Microbiology}

Figure 1(a) reports the growth of lactic acid bacteria (LAB) in olives. In particular, in the batches inoculated with the starter (T2-T4 and T5), cell counts were 4 $\log \cdot \mathrm{cfu} / \mathrm{g}$ higher than in the control after 7 days, whereas the difference was not significant after 21 days, as the population attained 5 to $5.75 \log \cdot \mathrm{cfu} / \mathrm{g}$ in all the samples, except for the batch inoculated with yeasts (T3) showing a LAB count $1 \log \cdot \mathrm{cfu} / \mathrm{ml}$ lower.

Concerning brines (Figure 1(b)), LAB were ca. 6 $\log \cdot \mathrm{cfu} / \mathrm{ml}$ just after inoculum in the batches T2, T4 and T5. Moreover, after 7 days inoculated samples showed a LAB count higher than un-inoculated ones, while the differences were not significant after 14 days.

Figure 2 shows yeast evolution in brine. As expected, after 7 days the highest cell number was observed in the inoculated batches (T3, T4 and T5), with a cell load ranging from 5.6 to $6.6 \mathrm{log} \cdot \mathrm{cfu} / \mathrm{ml}$; otherwise, in the un-inoculated samples (T1 and T2) yeast number was approximately 4.3 to $5.3 \mathrm{log} \cdot \mathrm{cfu} / \mathrm{ml}$. As reported for LAB, the difference between inoculated and inoculated batches was not significant after 14 days. A similar trend was recovered in olives (data not shown).

Enterobacteriaceae were at $3 \log \cdot \mathrm{cfu} / \mathrm{g}$ in olives and 4 $\log \cdot \mathrm{cfu} / \mathrm{ml}$ in brines, whereas pseudomonads, staphylococci and spore-former bacteria were at low levels (1 - 2 $\log \cdot \mathrm{cfu} / \mathrm{ml}$ ) or below the detection limit for the entire running time (data not shown).

\section{2. $\mathrm{pH}$}

Figure 3 shows $\mathrm{pH}$ values of olives. After 7 days, olives showed a pH of about 7 in the batches T2, T5 as well as in the control, whereas the $\mathrm{pH}$ was ca. 8 in the samples $\mathrm{T} 3$ and T4. After 2 week pH was ca $6-6.5$ and decreased until 5 at the end of fermentation, without significant differences amongst the different samples. A similar trend was recovered in brines (data not shown).

\subsection{Organic Acid Content}

Figures 4(a) and (b) show the concentration of D- and L-lactic acids in the brine; both L- and D-lactic acids increased significantly after 21 days of fermentation, then they decreased by $2-3 \mathrm{~g} / \mathrm{l}$; namely, in the sample T2 (sample inoculated with LAB) the concentration of L and D-lactic acids was the highest one $(9.15$ and $4.70 \mathrm{~g} / \mathrm{l})$, whereas the acids were at the lowest levels in the sample inoculated with a high level of yeasts.

Regarding acetic acid, its concentration increased throughout the entire fermentation, without any difference amongst the various batches (Figure 5). Finally, D-glucose and D-fructose decreased during the fermentation until to about $0.5 \mathrm{~g} / \mathrm{l}$ or below the detection limit (data not shown).

\section{Discussion}

\subsection{Why This Research?}

The use of a starter culture could shorten the processing 


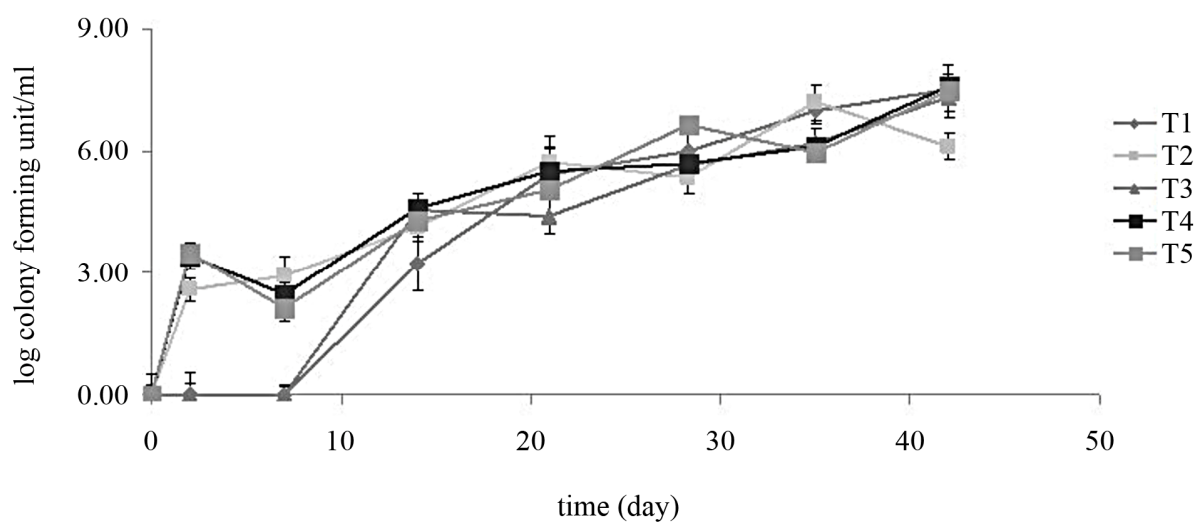

(a)

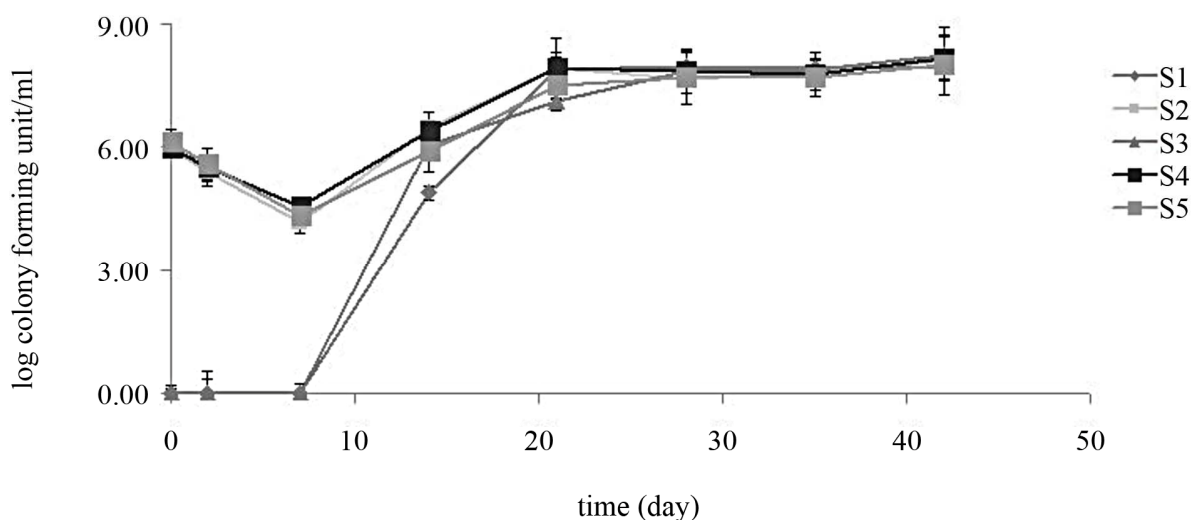

(b)

Figure 1. LAB microflora in olives (a) and brines (b). Mean values \pm standard deviation.

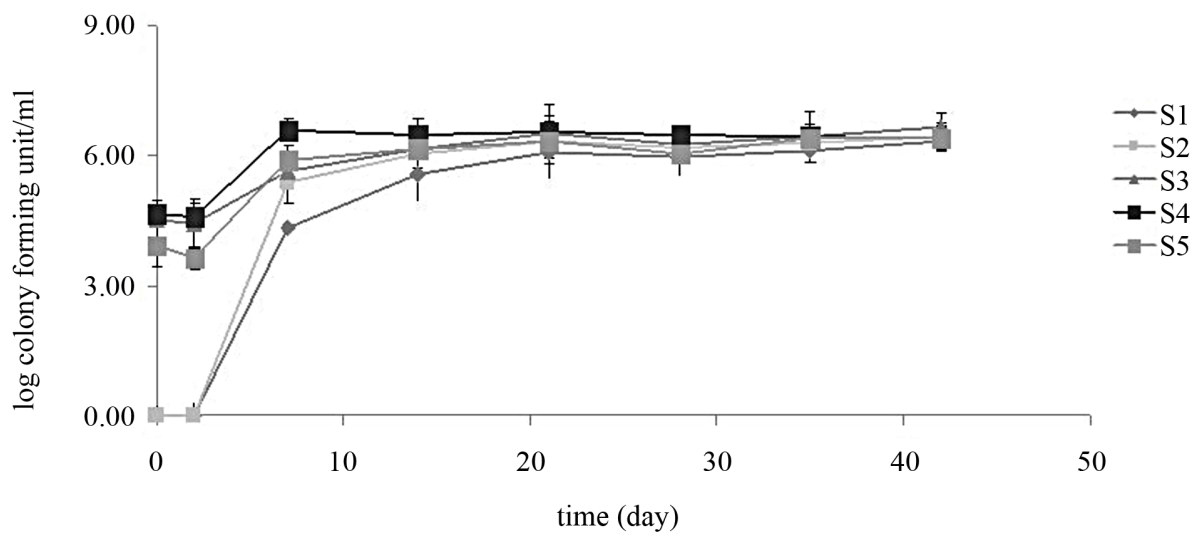

Figure 2. Yeast microflora in brines. Mean values \pm standard deviation.

time for the preparation of naturally green olives and affects positively fermentation, acidification rate and flavour of the product [7].

Many authors recommended the inoculation of brine with starter colture; in particular, the use of suitable strains of $L b$. plantarum could assure a correct course of fermentation [6-9]. Some benefits could be obtained also by a controlled inoculum of yeasts [10]. However, the focus of this study is different, as this research presents a new perspective on the use of starter cultures.
Many food producers select promising strains jointly with Universities and Research Centres; the main result of these collaboration is the selection of "the best strains". In the past a joint venture of the section of Applied Microbiology (University of Foggia) and some food producers of table olives of Apulian region resulted in the selection of some promising strains of lactic acid bacteria with interesting functional traits [2] and the evaluation of the technological and spoiling impact of yeast strains of Bella di Cerignola table olives [2]. Following these results, 


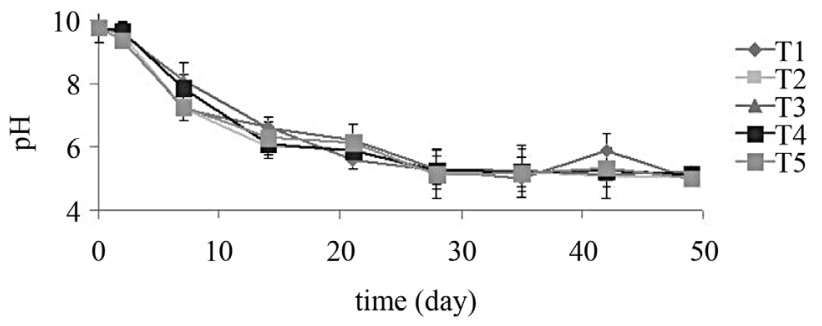

Figure 3. pH of olives. Mean values \pm standard deviation.

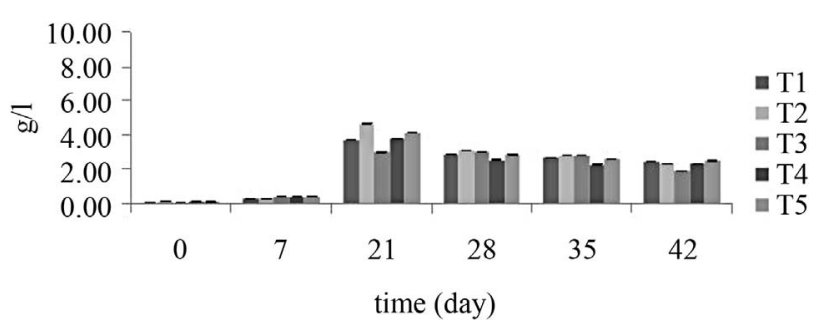

(a)

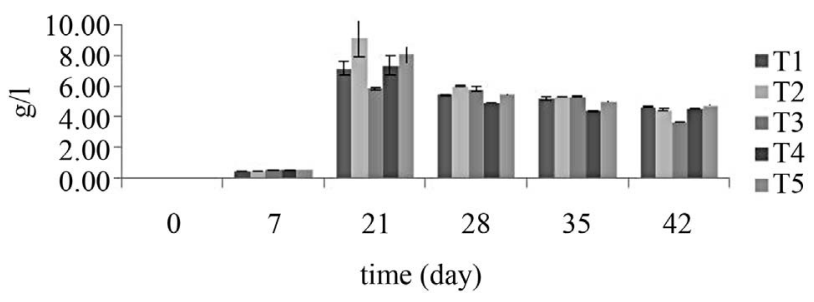

(b)

Figure 4. Content of $\mathrm{D}$ - and L-lactic acids (g/l) in the brine. (a) D-lactic acid; (b) L-lactic acid. Mean values \pm standard deviation.

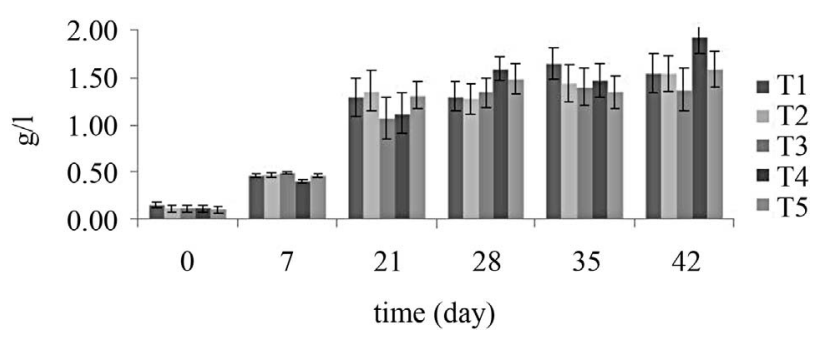

Figure 5. Content of acetic acid (g/l) in the brine. Mean values \pm standard deviation.

lactic acid bacteria and yeasts were suggested to producers for a controlled fermentation; however, what happened was that producers reported a decrease of the technological impact of these strains under in vivo conditions. After a brief evaluation of the problem in our lab, we supposed that the same strains, showing optimal performances in a lab fermentation, could be affected in a real fermentation by the way of the preparation of inoculum; thus, we prepared the starters in the same way reported by producers (strain cultivation in lab media, followed by harvesting and cell suspension in brine).

The initial planning included also some batches inoculated with starters, grown in media containing in- creasing concentration of salt; then, we decided to delete these samples, as the main aim of the research was to verify if also under lab conditions the strains behave in the same way than in factories.

What we found was that, as suggested by many producers, the differences between inoculated and inoculated samples were significant only for 2 - 3 weeks of fermentation (cell number, $\mathrm{pH}$, content of lactic acid); after this time, the samples inoculated with the starter showed the same trend than the uninoculated ones. A practical implication of this result is that a preliminary adaptation could be useful to assure the success of the starter for the entire process. A particular kind of adaptation is the back-slopping, i.e. inoculation often carried out with brines from previous fermentations [11]. However, such lactic cultures exhibit a diversity of metabolic activities, even among strains of the same species, including differences in growth rate, adaptation to a particular substrate, antimicrobial properties, flavour and quality attributes as well as competitive growth behaviour in mixed cultures, resulting in non-consistent and low quality final products. This kind of protocol was used in the past by Italian producer of table olives; although the process run faster, the quality was not constant.

Another element confirming the strong implications of a not-correct use of the starter was the $\mathrm{pH}$; the $\mathrm{pH}$ in a safe table olive must be about 4.5. In our fermentation, $\mathrm{pH}$ decreased until to about 5 after 28 days, then it remained constant during the entire fermentation.

\section{Conclusion}

In conclusion, why this research? A possible answer: underline the risk associated with a not-correct use of the starter and the importance of a good step of starter preparation. Using the starter only after a growth phase in a laboratory medium could result a delay in this performances in brines.

\section{REFERENCES}

[1] A. Hurtado, C. Reguant, A. Bordons and N. Rozès, "Evaluation of a Single and Combined Inoculation of a Lactobacillus pentosus Starter for Processing cv. Arbequina Natural Green Olives," Food Microbiology, Vol. 27, No. 6, 2010, pp. 731-740. doi:10.1016/j.fm.2010.03.006

[2] A. Bevilacqua, M. Perricone, M. Cannarsi, M. R. Corbo and M. Sinigaglia, "Technological and Spoiling Characteristics of the Yeast Microflora Isolated from Bella Di Cerignola Table Olives," International Journal of Food Science and Technology, Vol. 44, No. 11, 2009, pp. 21982207. doi:10.1111/j.1365-2621.2009.02060.x

[3] D. Campaniello, A. Bevilacqua, D. D'Amato, M. R. Corbo, C. Altieri and M. Sinigaglia, "Microbial Charac- 
terization of Table Olives Processed According to Spanish and Natural Styles," Food Technology and Biotechnology, Vol. 43, No. 3, 2005, pp. 289-294.

[4] M. Perricone, A. Bevilacqua, M. R. Corbo and M. Sinigaglia, "Use of Lactobacillus plantarum and Glucose to Control the Fermentation of 'Bella di Cerignola' Table Olives, a Traditional Variety of Apulian Region (Southern Italy)," Journal of Food Science, Vol. 75, No. 5, 2010, pp. M430-M436. doi:10.1111/j.1750-3841.2010.01742.x

[5] A. Hernandèz, A. Martin, E. Aranda, F. Pèrez-Nevado and M. G. Còrdoba, "Identification and Characterization of Yeast Isolated from the Elaboration of Seasoned Green Table Olives," Food Microbiology, Vol. 24, No. 4, 2007, pp. 346-351. doi:10.1016/j.fm.2006.07.022

[6] M. Vega Leal-Sánchez, J. L. Ruiz-Barba, A. H. Sánchez, L. Rejano, R. Jiménez-Díaz and A. Garrido, "Fermentation Profile and Optimization of Green Olive Fermentation Using Lactobacillus pentosus LCPO10 as a Starter Culture," Food Microbiology, Vol. 20, 2003, pp. 421430.

[7] V. Marsilio, L. Seghetti, E. Iannucci, F. Russi, B. Lanza and M. Felicioni, "Use of Lactic Acid Bacteria Starter Culture during Green Olive (Olea europaea cv L. cv Ascolana tenera) Processing," Journal of the Science of
Food and Agriculture, Vol. 85, No. 7, 2005, pp. 1084 1090. doi:10.1002/jsfa.2066

[8] E. Medina, C. Romero, A. de Castro, M. Brenes and A. García, "Inhibitors of Lactic Acid Fermentation in Spanish-Style Green Olive Brines of the Manzanilla Variety," Food Chemistry, Vol. 110, No. 4, 2008, pp. 932-937. doi:10.1016/j.foodchem.2008.02.084

[9] A. Bevilacqua, C. Altieri, M. R. Corbo, M. Sinigaglia and L. I. I. Ouoba, "Characterization of Lactic Acid Bacteria Isolated from Italian Bella di Cerignola Table Olives: Selection of Potential Multifunctional Starter Cultures," Journal of Food Science, Vol. 75, No. 8, 2010, pp. M536M544. doi:10.1111/j.1750-3841.2010.01793.x

[10] F. N. Arroyo-López, J. Bautista-Gallego, M. C. DuránQuintana and A. Garrido-Fernández, "Modelling the Inhibition of Sorbic and Benzoic Acids on a Native Yeast Cocktail," Food Microbiology, Vol. 25, No. 4, 2008, pp. 566-574. doi:10.1016/j.fm.2008.02.007

[11] A. Aponte, G. Blaiotta, F. L. Croce, A. Mazzaglia, V. Farina, L. Settanni and G. Moschetti, "Use of Selected Autochthonous Lactic Acid Bacteria for Spanish-Style Table Olive Fermentation," Food Microbiology, Vol. 30, No. 1, 2012, pp. 8-16. doi:10.1016/j.fm.2011.10.005 